\title{
Attention shifts during matching-to-sample performance in pigeons
}

\author{
CHARLES R. LEITH and WILLIAM S. MAKI, JR. \\ University of California, Berkeley, California 94720
}

\begin{abstract}
Two pigeons performed a matching-to-sample task in which a color, a line orientation, or both, might appear on the sample. Stimulus control by (attention to) the color and line components of a compound sample was measured when (a) either component might be relevant (i.e., appear as a comparison stimulus on that trial), and (b) when only one component was relevant. Degree of stimulus control by a given component of the compound sample was higher when only it was relevant than when either component might be relevant. Because the matching-to-sample task separated sample inspection from response choice, interpretation of the results in terms of response competition was ruled out. Because the training procedure led to shifts in stimulus control by the components of the compound sample, explanation of previous matching-to-sample results in terms of reduced perceptual clarity of compound samples was also ruled out. Thus, variations in stimulus control by components of the compound sample were interpreted as showing shifts in attention to the components of the compound sample.
\end{abstract}

Selective attention is a hypothesis offered to account for the observation that stimulus control is often unequally distributed among simultaneously presented stimuli (see Sutherland \& Mackintosh, 1971). In selective attention models that borrow the concept of limited processing capacity from information-processing theory, control by a particular stimulus is achieved by deploying processing capacity ("attending") to that stimulus. When control by one stimulus uses the whole processing capacity, other stimuli are ignored (not processed), and selective attention is given to that one stimulus (Broadbent, 1961; Mackintosh, 1965). Such theories hold that in order to observe selective attention, control by a number of competing stimuli must so tax processing capacity that control by each of these stimuli must be reduced as attention is divided among them. Very few experiments have examined divided-attention performance in animals (Farthing \& Opuda, 1973; Maki \& Leuin, 1972; Maki \& Leith, 1973), and only one that we know of (Blough, 1969) has used performance in a divided-attention condition as a baseline from which to measure effects predicted by selective-attention theory.

Blough (1969) trained pigeons to perform a discrimination between compound stimuli made up of tones and colors. The birds were trained to attend to (come under control of) both elements of the compounds by reinforcing a conditional discrimination. For example, only during the compound of $3,990 \mathrm{~Hz}$ and $582 \mathrm{~nm}$ was pecking reinforced; pecking in the

This research was supported by DHEW grant 5-R01MH22153-01 to D. A. Riley, who gave intellectual, as well as material, support.

Address reprint requests to $C$. R. Leith. Current address is Department of Psychology, Northern Michigan University, Marquette, Michigan 49855.

William S. Maki, Jr. was supported by USPHS Predoctoral Traineeship MH10878; he is now at North Dakota State University. presence of the 48 other combinations of a 7 by 7 array was not reinforced. In order to train his birds to attend to only one dimension of the compound, Blough removed all negative instances of the competing dimension; for example, only those compounds containing tones of $3,990 \mathrm{~Hz}$ were presented. In this phase, the compounds to be discriminated were a subset of those used in the conditional discrimination, and the discrimination could be solved while ignoring the constant (irrelevant) component of the compound. The experiment proceeded by switching from the conditional discrimination task (or "divided-attention" task) to the one-relevant-dimension task (or "focused-attention" task) and back again to the conditional discrimination for several cycles.

Blough reported three effects that together support a selective-attention model: (1) birds discriminated more accurately along a given dimension when it alone was relevant than when it and another dimension were relevant, (2) upon return to the divided-attention task, stimulus control was temporarily reduced on the dimension made irrelevant in focused-attention training, and (3) stimulus control by a given dimension that improved during focused-attention training declined toward baseline upon return to the divided-attention task. These three facts together suggest that the birds could be trained to deploy attention toward one stimulus dimension and away from a competing dimension.

Blough's evidence would be convincing support for selective attention except that his paradigm confounds stimulus competition and response competition (Maki \& Leith, 1973). In Blough's divided-attention condition, the birds were often confronted by compounds which elicited conflicting response tendencies. For instance, the $\mathrm{S}+$ color value $(582 \mathrm{~nm})$ was compounded with any of six nonreinforced tone values, in which case the color 
would elicit a tendency to peck in conflict with the tone-elicited tendency to withhold pecking. In such a case, focused-attention training to color might simply bias the bird to choose the color response over the tone response. If the bird was biased to make the color response over the tone response, color control of behavior would be high and tone control of behavior would be masked. In the long-embattled history of selective attention (Riley, 1968), one issue has become very clear: Response-selection mechanisms are alternatives to stimulus-selection mechanisms in learning theory. Blough's data can be as readily taken to illustrate response selection as stimulus-selection mechanisms of behavior. Thus, it would be very useful to replicate Blough's effects in a paradigm which rules out a response-selection account of selective attention effects.

Maki and Leuin (1972) and Maki and Leith (1973) have developed a matching-to-sample (MTS) paradigm that shows loss of stimulus control in a divided-attention condition. In one version of this MTS paradigm, pigeons were reinforced for matching to both colors and line orientations in sample stimuli of several fixed durations (Maki \& Leith, 1973). On a random 50\% of the trials, both color and line orientation occurred in a compound sample. On such compound-sample trials (divided-attention condition), the birds were presented with twice as much information as on element-sample trials. Matching test choices were always between element stimuli from a single dimension. Thus, color- (or line-) matching performance could be measured following element samples (undivided attention) and compound samples (divided attention) at each sample duration. For each sample duration, color (or line) samples which occurred alone supported better matching performance than the same color (or line) samples when presented in compound. These data have been interpreted as evidence that information presented in compound samples taxes the birds' processing capacity (Maki \& Leuin, 1972). In order for compound-sample performance to equal element-sample performance under these conditions, the birds would have to process twice as much information from compound samples than from element samples in the time allowed.

If the MTS paradigm does produce loss of stimulus control due to divided attention in compound-cue trials, the conditions are met for showing Blough's attention-redeployment effects. Birds trained to focus attention to one dimension of the compound sample should show improved MTS performance on that dimension and reduced performance on the competing dimension following attentional training. The advantage of using the MTS paradigm over Blough's conditional-cue paradigm is that response choice is not confounded with attention to stimuli in the MTS design. At the moment of response choice, the bird is presented with only color- or line-element stimuli. Thus, matching choice reflects the bird's perception of the tested dimension in the sample, not a choice between conflicting responses elicited by competing cues on the response key. This separation of sample inspection and response choice enables the MTS paradigm to shed light on whether attention-like shifts in behavior are produced by changes in response competition or changes in attention deployment.

An alternative to the information-processing explanation of element-compound performance differences in the MTS paradigm is that the act of compounding elements simply degrades the perceptual clarity of each element (Zuckerman, 1973). This perceptual degradation hypothesis implies that manipulation of attention deployment will be unsuccesful because the limit on performance is the perceptual clarity of the sample and not information overload. Thus, replication of Blough's effects in the MTS paradigm would serve to rule out two hypotheses: (1) the hypothesis that Blough's effects are entirely due to response-choice mechanisms, and (2) the hypothesis that reduced MTS performance following compound samples is entirely due to perceptual degradation of elements in compound stimuli.

\section{METHOD}

\section{Subjects}

The subjects were two White Carneaux pigeons (Nos. 67 and 69) used in previous MTS experiments (Maki \& Leith, 1973; Maki \& Leuin, 1972). This prior experience provided baseline data for the present experiment. These birds received all of their daily food ration as food reinforcement for correct performance. This procedure maintained their weight at $85 \%-90 \%$ of their free-feeding weight.

\section{Apparatus}

The pecking keys, three-key pigeon operant-conditioning chamber, in-line stimulus projectors, and the controlling computer were all commercially available units described in detail elsewhere (Maki \& Leith, 1973). The element stimuli projected onto the pecking keys were a red field, a blue field, three vertical white lines on black, and three horizontal white lines on black. Compound stimuli were constructed by simultaneously projecting a color and a line orientation, yielding, for instance, three vertical white lines on a red field.

\section{Procedure}

Each trial started with presentation of a white center key. A peck on the white center key resulted in immediate presentation of a sample. The sample stimulus, presented on the center key, was either an element or a compound. After a specified time, independent of pecking, the sample key darkened and the two side keys displayed comparison stimuli. The comparison choice was always between either the two line orientations or the two colors. When the sample was an element, the comparison stimuli were always from the appropriate dimension. A correct (matching) response was a peck on the side key containing the line orientation or color that appeared on the sample. Correct responses terminated the comparison stimuli and were reinforced on a variable ratio (VR-2) schedule. Reinforcement was $1.8 \mathrm{sec}$ access to mixed grain. Incorrect responses terminated the comparison stimuli after a delay of $2 \mathrm{sec}$. A 5 -sec blackout separated the end of one trial from the start of the next trial.

Training was in blocks of six daily sessions. Each session consisted of 320 trials. During the 1st day of each block, sample duration was fixed at $5 \mathrm{sec}$. For the remaining five sessions, sample duration during the 64 warm-up trials was $2.56 \mathrm{sec}$, and varied during later trials $(.04, .08, .12, .16, .24, .32, .64$, $2.56 \mathrm{sec})$. Each day there was an equal number of element and 
compound samples at each duration, and the two values within each dimension were correct matching choices equally often. Within these restrictions, test trials were random with regard to side of correct choice, stimulus appearing on side key, order of sample durations, and occurrence of element or compound samples.

Both birds received a sequence of five training conditions. Each condition was in force for at least five blocks of sessions (30 days). In the mixed (M) condition, described above and in detail by Maki and Leith (1973), values from both the line orientation ( $\mathrm{L}$ ) and color (C) dimensions appeared in element, compound, and comparison stimuli. In the line-only (LO) condition, color values appeared only as one (irrelevant) component of compound samples and never as comparison stimuli. In the color-only (CO) condition, line-orientation values only appeared as an irrelevant component of a compound sample and never as comparison stimuli. The sequence of conditions $\left(\mathrm{M}_{1}, \mathrm{LO}, \mathrm{M}_{2}, \mathrm{CO}, \mathrm{M}_{3}\right)$ and the dimensions appearing in sample and comparison stimuli under each condition are summarized in Table 1. The $M$ conditions are divided-attention conditions and the LO and CO conditions correspond to Blough's (1969) focused-attention conditions. The $\mathrm{M}_{1}$ condition was maintained for 60 days, and data from this period reported in Maki and Leith (1973). Only the last 30 days of $M_{1}$ are reported in this paper.

The hypothesis in this experiment states that the differences between MTS accuracy on a color- (or line-) element sample and the same color (or line) appearing in a compound sample is produced by division of attention between the components of the compound. The cost of divided attention was measured by
Table 1

Sequence of Training Conditions Experienced by Both Birds

\begin{tabular}{llcc}
\hline & $\begin{array}{l}\text { Element } \\
\text { Samples }\end{array}$ & $\begin{array}{c}\text { Compound Comparison } \\
\text { Samples }\end{array}$ & Stimuli \\
\hline Mixed $\left(\mathrm{M}_{1}\right)$ & $\mathrm{L}, \mathrm{C}$ & $\mathrm{L}+\mathrm{C}$ & $\mathrm{L}, \mathrm{C}$ \\
Line Only $(\mathrm{LO})$ & $\mathrm{L}$ & $\mathrm{L}+\mathrm{C}$ & $\mathrm{L}$ \\
Mixed $\left(\mathrm{M}_{2}\right)$ & $\mathrm{L}, \mathrm{C}$ & $\mathrm{L}+\mathrm{C}$ & $\mathrm{L}, \mathrm{C}$ \\
Color Only $(\mathrm{CO})$ & $\mathrm{C}$ & $\mathrm{L}+\mathrm{C}$ & $\mathrm{C}$ \\
Mixed $\left(\mathrm{M}_{3}\right)$ & $\mathrm{L}, \mathrm{C}$ & $\mathrm{L}+\mathrm{C}$ & $\mathrm{L}, \mathrm{C}$ \\
\hline
\end{tabular}

Note-Presence of color (C) and line ( $L$ ) values in each type of sample and in comparison stimuli is shown for each condition.

subtracting performance on compound-sample trials from performance on element-sample trials at each sample duration. The element-minus-compound difference score, or compound decrement, should approach zero if attention is focused on the relevant component of compound samples in $\mathrm{LO}$ or CO training, and should grow large if attention is deployed away from the tested dimension in compound trials. The compound decrement score uses element performance as a baseline of current potential stimulus control, so that factors (such as practice) which might cause absolute MTS performance to vary over days are controlled.

\section{RESULTS AND DISCUSSION}

Table 2 shows the performance of each bird on each dimension during each phase of the experiment. The

Table 2

Percent Correct Performance on MTS Following Line Element Samples (LE), Line Compound Samples (LC), Color Element Samples (CE), and Color Compound Samples (CC) for Each Bird, at Each Sample Duration, in Each Training Condition

\begin{tabular}{|c|c|c|c|c|c|c|c|c|c|c|c|}
\hline & & \multicolumn{5}{|c|}{$\begin{array}{c}\text { Bird } 67 \\
\text { Sample Duration in Seconds }\end{array}$} & \multicolumn{5}{|c|}{$\begin{array}{c}\text { Bird } 69 \\
\text { Sample Duration in Seconds }\end{array}$} \\
\hline & & $.04-.08$ & $.12-.16$ & $.24-.32$ & $.64-2.56$ & 5.0 & $.04-.08$ & $.12-.16$ & $.24-.32$ & $.64-2.56$ & 5.0 \\
\hline $\mathrm{M}_{1}$ & $\begin{array}{l}\text { LE } \\
\text { LC } \\
D \\
C E \\
C C \\
D\end{array}$ & $\begin{array}{r}61 \\
54 \\
7 \\
61 \\
57 \\
4\end{array}$ & $\begin{array}{r}74 \\
65 \\
9 \\
81 \\
76 \\
5\end{array}$ & $\begin{array}{r}87 \\
79 \\
8 \\
90 \\
79 \\
11\end{array}$ & $\begin{array}{r}96 \\
92 \\
4 \\
93 \\
90 \\
3\end{array}$ & $\begin{array}{r}97 \\
93 \\
4 \\
97 \\
89 \\
8\end{array}$ & $\begin{array}{r}64 \\
59 \\
5 \\
62 \\
61 \\
1\end{array}$ & $\begin{array}{l}75 \\
65 \\
10 \\
74 \\
75 \\
-1\end{array}$ & $\begin{array}{c}86 \\
75 \\
11 \\
80 \\
81 \\
-1\end{array}$ & $\begin{array}{r}93 \\
85 \\
8 \\
85 \\
84 \\
1\end{array}$ & $\begin{array}{r}97 \\
93 \\
4 \\
94 \\
93 \\
1\end{array}$ \\
\hline LO & $\begin{array}{l}\text { LE } \\
\text { LC } \\
\text { D }\end{array}$ & $\begin{array}{r}61 \\
55 \\
6\end{array}$ & $\begin{array}{r}78 \\
70 \\
8\end{array}$ & $\begin{array}{r}90 \\
85 \\
5\end{array}$ & $\begin{array}{r}97 \\
96 \\
1\end{array}$ & $\begin{array}{r}96 \\
95 \\
1\end{array}$ & $\begin{array}{r}62 \\
53 \\
9\end{array}$ & $\begin{array}{l}77 \\
67 \\
10\end{array}$ & $\begin{array}{l}88 \\
78 \\
10\end{array}$ & $\begin{array}{r}95 \\
90 \\
5\end{array}$ & $\begin{array}{r}98 \\
97 \\
1\end{array}$ \\
\hline $\mathbf{M}_{2}$ & $\begin{array}{l}\text { LE } \\
\text { LC } \\
D \\
C E \\
C C \\
D\end{array}$ & $\begin{array}{r}65 \\
59 \\
6 \\
63 \\
63 \\
0\end{array}$ & $\begin{array}{r}87 \\
78 \\
9 \\
88 \\
81 \\
7\end{array}$ & $\begin{array}{r}93 \\
87 \\
6 \\
93 \\
83 \\
10\end{array}$ & $\begin{array}{r}96 \\
94 \\
2 \\
96 \\
90 \\
6\end{array}$ & $\begin{array}{r}96 \\
93 \\
3 \\
97 \\
81 \\
16\end{array}$ & $\begin{array}{r}63 \\
54 \\
9 \\
60 \\
58 \\
2\end{array}$ & $\begin{array}{r}84 \\
68 \\
16 \\
73 \\
69 \\
4\end{array}$ & $\begin{array}{r}93 \\
84 \\
9 \\
82 \\
80 \\
2\end{array}$ & $\begin{array}{r}94 \\
88 \\
6 \\
87 \\
82 \\
5\end{array}$ & $\begin{array}{r}100 \\
98 \\
2 \\
97 \\
91 \\
6\end{array}$ \\
\hline $\mathrm{CO}$ & $\begin{array}{l}\mathrm{CE} \\
\mathrm{CC} \\
\mathrm{D}\end{array}$ & $\begin{array}{r}65 \\
67 \\
-2\end{array}$ & $\begin{array}{r}89 \\
82 \\
7\end{array}$ & $\begin{array}{r}95 \\
89 \\
6\end{array}$ & $\begin{array}{r}96 \\
91 \\
5\end{array}$ & $\begin{array}{l}98 \\
88 \\
10\end{array}$ & $\begin{array}{r}67 \\
67 \\
0\end{array}$ & $\begin{array}{r}84 \\
81 \\
3\end{array}$ & $\begin{array}{r}91 \\
89 \\
2\end{array}$ & $\begin{array}{r}91 \\
89 \\
2\end{array}$ & $\begin{array}{r}97 \\
96 \\
1\end{array}$ \\
\hline $\mathbf{M}_{3}$ & $\begin{array}{l}\text { LE } \\
\text { LC } \\
D \\
C E \\
C C \\
D\end{array}$ & $\begin{array}{r}69 \\
52 \\
17 \\
70 \\
61 \\
9\end{array}$ & $\begin{array}{r}86 \\
77 \\
9 \\
96 \\
83 \\
13\end{array}$ & $\begin{array}{r}95 \\
89 \\
6 \\
96 \\
92 \\
4\end{array}$ & $\begin{array}{r}95 \\
94 \\
1 \\
98 \\
94 \\
4\end{array}$ & $\begin{array}{r}98 \\
92 \\
6 \\
98 \\
93 \\
5\end{array}$ & $\begin{array}{r}63 \\
57 \\
8 \\
67 \\
65 \\
2\end{array}$ & $\begin{array}{r}76 \\
65 \\
11 \\
82 \\
77 \\
5\end{array}$ & $\begin{array}{r}87 \\
78 \\
9 \\
88 \\
84 \\
4\end{array}$ & $\begin{array}{r}95 \\
86 \\
9 \\
93 \\
91 \\
2\end{array}$ & $\begin{array}{r}100 \\
96 \\
4 \\
98 \\
98 \\
0\end{array}$ \\
\hline
\end{tabular}

Note- $M_{1}, M_{2}$, and $M_{3}$ are mixed conditions, $L O$ and $C O$ are line only and color only conditions. The difference (D) between element and compound sample performance at each sample duration is compound decrement score. 


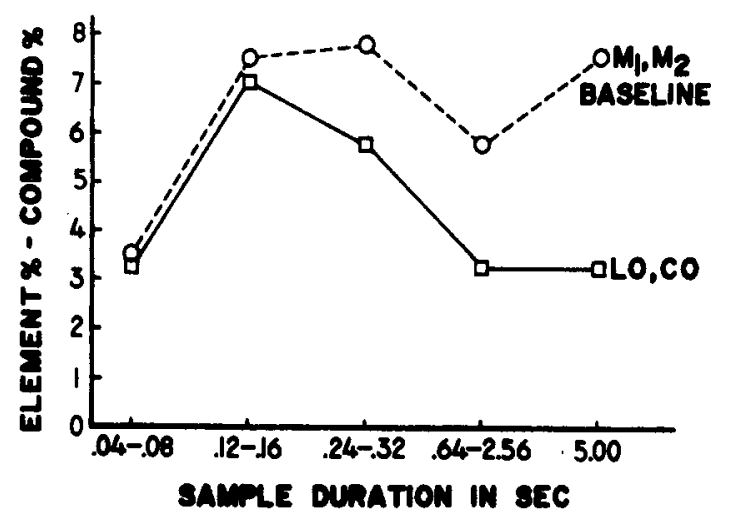

Figure 1. Change in compound decrement (element-sample percent minus compound-sample percent) from $M_{1}$ and $M_{2}$ conditions to LO and $\mathrm{CO}$ conditions as a function of sample duration. Baseline curve shows average, over both birds, of line performance in $M_{1}$ and color performance in $M_{2}$. LO,CO curve shows average of line performance in LO and color performance in $\mathrm{CO}$.

bulk of this table has been reduced somewhat by averaging together the performances at adjacent sample durations presented during variable-duration sessions. Each reported percentage is based on 400 test trials except for performance at the 5-sec sample duration which is based on 320 test trials. Separate consideration of element and compound scores shows no large or consistent effect of the sequence of training conditions other than a general tendency to improve performance over the 5-month period of testing. The dependent variable in this experiment is compound decrement (also shown in Table 2), and this measure of compound performance does reveal a pattern of change as a function of training condition.

Figure 1 shows the change (averaged over birds and dimensions) in compound decrement scores produced by focused-attention training as a function of sample duration. The LO,CO curve shows that there is a reduction in compound decrement (relative to baseline performance) under LO and CO conditions. Inspection of Table 2 shows that, of 20 opportunities to observe a change in compound decrement during focused-attention training ( 2 birds by 2 dimensions by 5 durations), there are 16 instances of reduction, 3 no change, and 1 increase. This tendency to decrease compound decrement scores during LO and $\mathrm{CO}$ conditions is statistically significant (sign test, 16/20, $\mathrm{p}=.012$ ). Such an improvement in compound performance is not compatible with the perceptual degradation hypothesis. An interesting feature of Figure 1 is that the effects of attention training appear to be larger at long sample durations than at short sample durations. Training effects were not only small on the average at short durations but also showed poor consistency across birds and dimensions (three of the four cases of no improvement during $\mathrm{LO}$ and $\mathrm{CO}$ training occur at sample durations below $.24 \mathrm{sec}$ ). The apparent relationship between sample duration and training effect was tested by calculating the $F$ ratio of improvement at short (below $.24 \mathrm{sec}$ ) durations vs. improvement at longer durations. Using the assumptions of a repeated-measures model, the $F$ of improvement scores for short vs. long durations was $10.8(\mathrm{df}=1,4$, $\mathrm{p}<.05$ ). Thus, the data displayed in Figure 1 suggest that we can safely reject the perceptual degradation hypothesis only for sample durations greater than $.24 \mathrm{sec}$.

Figure 2 shows the average compound decrement scores obtained on each dimension during each stage of the experiment. These scores are averaged over both birds and represent performance at sample durations of $.24 \mathrm{sec}$ or greater. In Figure 2, as in Figure 1, there is a sharp reduction in compound decrement scores when only one dimension is relevant. In addition, Figure 2 shows an increase in compound decrement scores on the dimension made irrelevant during focused-attention training upon return to a mixed condition. Inspection of Table 2 shows that increase in compound decrement on the irrelevant dimension following focused-attention training are, on the average, larger and are more consistent at longer sample durations. In general, these data suggest that reductions in compound decrement on one dimension (produced by focused-attention training) are accompanied by increases in compound decrement on the competing dimension. Such an inverse relationship is required by a limited-processing-capacity model of attention. We must note, however, that the averaged data in Figure 2 do not necessarily represent a strong inverse relationship. One way to show the degree

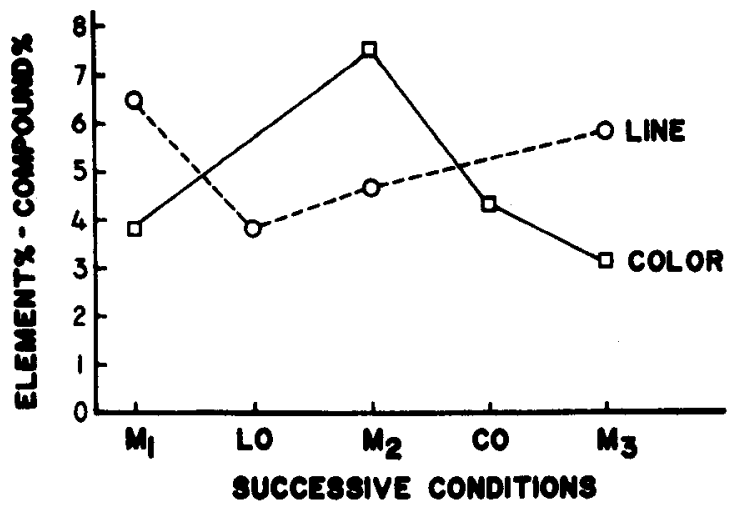

Figure 2. Compound decrement (element percent minus compound percent) in each dimension as a function of training conditions. Data averaged over two birds and over five longest sample durations. Compound decrement in line performances decreased in LO condition, increased upon return to $\mathbf{M}_{2}$ condition and increased again following $\mathrm{CO}$ (line irrelevant) condition. Compound decrement in color performance increased following LO (color irrelevant) condition, decreased in $\mathrm{CO}$ condition, and shows decrease upon return to $\mathbf{M}_{3}$ condition. Individual birds show same pattern except Bird 69 increased color compound decrement in $\mathrm{CO}$ to $\mathrm{M}_{3}$ transition. 
of inverse relation is to calculate a correlation between change in compound decrement on one dimension and change in decrement on the competing dimension. Such a correlation was calculated on changes in compound decrement for sample durations above $.24 \mathrm{sec}$. Change was calculated as the difference in compound decrement scores taken before and after a focused-attention stage. This correlation was $\mathrm{r}=-.75(\mathrm{p}<.05)$, indicating that large gains on one dimension are balanced by large losses on the competing dimension, in accord with the inverse relationship.

The data discussed above replicate two of the effects reported by Blough, namely, improvement on the relevant dimension during focused-attention training and reduction in control by the dimension made irrelevant during focused-attention training. The third effect reported by Blough, reduction in control by the dimension receiving focused-attention training upon return to the mixed condition, was observed in both birds in the LO to $\mathrm{M}_{2}$ transition, and (rather weakly) in one bird in the $\mathrm{CO}$ to $\mathrm{M}_{3}$ transition. Each of the birds had the opportunity to display the three effects reported by Blough on each of two dimensions. Thus, there are 12 opportunities to observe disconfirming data. The data reported in Figure 2 replicate Blough in 11 of those 12 instances.

The effects of focused-attention training on control by the elements of a compound stimulus are much the same in Blough's (1969) paradigm and in the present MTS paradigm. The data replicating Blough, however, were obtained only from the five longer duration sample stimuli. There are at least three possible interpretations for this duration effect. One hypothesis is that because stimulus control is so poor at short durations, the data are too variable to provide a reliable demonstration of the phenomena. A second hypothesis is that perceptual degradation of the compound determines performance at short sample durations. Both of the above hypotheses suggest that data from long sample durations may be taken at face value.

A third hypothesis is suggested by the observation that there may be a performance ceiling at long sample durations (Table 2), and that element performance is nearer the ceiling than is compound performance. The hypothesis states that element and compound performances improve equally during $\mathrm{LO}$ and $\mathrm{CO}$ training, but that measurable improvement in element performance is prevented by the ceiling effect. Thus, LO and $\mathrm{CO}$ training appears to reduce compound decrement scores.
The ceiling-effect hypothesis is a plausbile explanation of the reduction in compound decrement (see Figure 1) during $\mathrm{LO}$ and $\mathrm{CO}$ training in the present experiment. A ceiling effect during focused-attention training, however, does not provide a simple account of the increase in compound decrement scores on the irrelevant dimensions (see Figure 2). In addition, an analysis of performance changes at selected sample durations seriously weakens the ceiling-effect hypothesis. In this comparison, compound-sample performances averaging about $86 \%$ correct were matched with shorter duration element performances averaging $86 \%$ correct in the $M$ condition. When shifted to LO or CO conditions, the compound-sample-performance improvement was clearly greater than the element-sample-performance improvement. Thus, even when matched for initial distance from the ceiling, compound performance improves more than element performance during LO and $\mathrm{CO}$ conditions.

We conclude that the selective attention behavior reported by Blough (1969) can be replicated under conditions that rule out a response-bias account of the data. In addition, the finding of attention shifts in the MTS paradigm serves to rule out a perceptual degradation account of compound-sample performance, at least for sample durations above $.24 \mathrm{sec}$. We infer that compound-sample performance is reduced by divided attention in the mixed condition, and that this attention deployment can be at least partially modified by focused-attention training.

\section{REFERENCES}

Blough, D. S. Attention shifts in a maintained discrimination. Science, 1969, 166, 125-126.

Broadbent, D. E. Human perception and animal learning. In $W$. H. Thorpe and O. L. Zangwill (Eds.), Current problems in animal behavior. Cambridge: The University Press, 1961.

Farthing, G. W., \& Opuda, M. J. Selective attention in matching-to-sample in pigeons. Paper presented at the meeting of the Eastern Psychological Association, Washington, D. C., 1973.

Mackintosh, N. J. Selective attention in animal discrimination learning. Psychological Bulletin, 1965, 64, 124-150.

Maki, W. S., Jr., \& Leith, C. R. Shared attention in pigeons. Journal of the Experimental Analysis of Behavior, 1973, 19, 345-349.

Maki, W. S., Jr., \& Leuin, T. C. Information-processing by pigeons. Science, 1972, 176, 535-536.

Riley, D. A. Discrimination learning. Boston: Allyn and Bacon, 1968.

Sutherland, N. S., \& Mackintosh, N. J. Mechanisms of animal discrimination learning. New York: Academic Press, 1971.

Zuckerman, D. C. Steady state responding based on simple and compound stimuli. Journal of the Experimental Analysis of Behavior, 1973, 20, 209-218.

(Received for publication March 4, 1974; revision accepted September $5,1974$. ) 